Neurosurg Focus 9 (1):Article 6, 2000, Click here to return to Table of Contents

\title{
Cerebrospinal fluid volume depletion and its emerging clinical/imaging syndromes
}

\author{
BAHRAM MOKRI, M.D. \\ Department of Neurology, Mayo Clinic, Rochester, Minnesota
}

\begin{abstract}
Cerebrospinal fluid (CSF) volume depletion, due to CSF leakage or CSF shunt overdrainage, is typically indicated when patients present with orthostatic headaches, with or without several other symptoms: neck or interscapular pain, nausea, emesis, diplopia, changes in hearing, visual blurring, facial numbness or weakness, and radicular upper-limb symptoms. Cerebrospinal fluid pressures typically are quite low and head magnetic resonance images typically reveal diffuse pachymeningeal gadolinium enhancement, with or without evidence of sagging of the brain and less frequently with subdural fluid collections, enlarged cerebral venous sinuses or pituitary gland or decreased ventricular size.

Magnetic resonance imaging has revolutionized detection of spontaneous CSF leaks, leading to identification of far more cases and recognition of several clinical/imaging forms of presentation of the disorder. These forms, which are different from the "typical" presentation, include a group with consistently normal CSF pressures (normal pressure), another group without abnormal meningeal enhancement (normal meninges), and a group without headache (acephalic). Each of these forms can be seen in a setting of documented and ongoing CSF volume depletion. Awareness of CSF volume depletion is increasing, and its clinical and imaging spectrum is broadening.
\end{abstract}

\section{KEY WORDS - cerebrospinal fluid leak - cerebrospinal fluid volume depletion • intracranial hypotension • Chiari malformation • orthostatic headache}

It has barely been a decade since the first report on meningeal gadolinium enhancement and CSF leaks appeared in the literature. ${ }^{30}$ In this short time, a large number of patients with spontaneous CSF leaks have been identified, and a broader clinical and neuroimaging spectrum of the disease has been recognized. ${ }^{26}$ Many clinicians have treated a much larger number of such patients than before and might have wondered where all these patients were only 1 to 2 decades ago. ${ }^{9}$ There is little doubt that, prior to the first report, ${ }^{31}$ the diagnosis was frequently missed. Many patients improved spontaneously while a significant minority endured a considerably compromised quality of life, visiting a variety of specialists, pain management facilities, and so forth. Occasionally patients even underwent decompressive surgeries for a presumed Chiari I malformation, and little benefit was thereafter provided.

Magnetic resonance imaging of the head and spine has truly revolutionalized the identification, diagnosis, management, and follow-up evaluation of patients with spontaneous CSF leaks and, additionally, has increased our overall understanding of CSF volume depletion. Several clinical-neuroimaging forms of CSF volume depletion due to spontaneous CSF leakage or overdraining CSF shunts have been recognized.

\section{HISTORICAL ASPECTS}

In 1891 Quinke introduced the lumbar puncture, ${ }^{50}$ and

\footnotetext{
Abbreviations used in this paper: $\mathrm{CSF}=$ cerebrospinal fluid; $\mathrm{CT}$ = computerized tomography; $\mathrm{MR}=$ magnetic resonance.
}

in 1898 Bier suffered from lumbar puncture-related headaches and was the first to report them. ${ }^{41}$ George Schaltenbrand, a German neurologist, in a German-language article in $1938^{45}$ and in an English-language article in $1953^{46}$ emphasized the term "aliquorrhea," a condition marked by very low, unobtainable, or even negative CSF pressures that were clinically manifested by orthostatic headaches and other features that later came to be recognized as spontaneous intracranial hypotension. A few decades earlier the same syndrome had been described in the French literature as "hypotension of spinal fluid" or "ventricular collapse." ${ }^{" 46}$ Initially it was theorized that the cause of aliquorrhea or spontaneous intracranial hypotension was decreased CSF production or increased CSF absorption. However, modern evidence has not provided support for either theory, but it has implicated CSF leakage. Understandably the technology of the time could not have allowed Schaltenbrand or his contemporaries to assess patients adequately for CSF leakage. ${ }^{11}$

In the United States, as early as 1940, Henry Woltman ${ }^{58}$ of the Mayo Clinic wrote about "headaches associated with decreased intracranial pressure" and gave a concise description of the syndrome, stating that "occasionally an occipital or frontal headache comes on only when the patient is up and about and leaves when the patient lies down. Such a headache is often associated with low pressure of the spinal fluid. Thus, it resembles post-puncture headache." It is clear, therefore, that in this country the entity was quite known to some clinicians in 1930s if not earlier.

The full clinical manifestations of intracranial hypoten- 
sion or CSF leak were described in several publications reported between the 1960s and early 1990 s. . $^{2,5,21,23,24,40}$ The introduction of radioisotope cisternography, ${ }^{12,22,33,34,57} \mathrm{wa}-$ ter-soluble myelography, and CT myelography provided the clinicians with more effective tools to diagnose and locate CSF leaks. In the 1990s we learned of the discovery of MR imaging-documented abnormalities in CSF volume depletion due to CSF leakage or CSF shunt overdrainage. ${ }^{12,19,30,36,44}$ All of these discoveries have resulted in broader recognition of the syndrome and its variations.

\section{ETIOLOGICAL CHARACTERISTICS}

Cerebrospinal fluid volume depletion related to CSF shunt overdrainage or posttraumatic or postsurgical CSF leaks is well recognized. More intriguing are the CSF leaks that develop spontaneously. The majority of these occur in the thoracic spine or at the cervicothoracic junction; leaks occurring at other levels of spine are less common, and those demonstrated at the skull base are by far the least frequent.

In spontaneous CSF leaks the exact cause often remains unknown, but two contributing factors are frequently suspected: 1) weakness of meningeal sac in certain regions and 2) trivial traumatic injury.

A history of trivial traumatic injury is reported by many, although not the majority of patients with spontaneous CSF leaks. The following observations implicate focal weakness of thecal sac in some of these patients, which may be related to abnormality or deficiency of elastin or fibrillin in some of them: CSF leaks in Marfan syndrome, ${ }^{7}$ marfanoid features in some patients with CSF leaks, history of retinal detachment at young age, ${ }^{32}$ frequent detection of meningeal diverticula, sometimes multiple, and diverticula in certain inheritable disorders of connective tissue ${ }^{7,10,14,48}$ Occasionally, a dural tear caused by a spondylotic spur may lead to CSF leak. ${ }^{56}$

\section{CLINICAL MANIFESTATIONS}

The typical clinical manifestation in CSF volume depletion is orthostatic headache-a headache that typically occurs when the patient is upright and relieved by recumbency. It may be bifrontal, occipital, occipital and bifrontal, or holocephalic, and it may or may not be throbbing. Variability in the form of headache, however, is considerable. Sometimes, particularly in patients with chronic headache, the orthostatic features may blur and the headache may take the form of a lingering chronic daily headache that may or may not be more pronounced in upright position. Sometimes the headache may begin as a lingering headache, and typical orthostatic features may appear days or weeks later. At times the headache may be preceded by neck pain or interscapular pain for days or weeks. In patients with intermittent CSF leaks, the headaches (and any of the just-described features) may disappear for variable periods and reappear again.

Other headache-related clinical manifestations in patients with CSF volume depletion include neck pain or stiffness, sometimes with orthostatic features; nausea and sometimes emesis, often orthostatic; diplopia, which is typically horizontal and due to unilateral or bilateral sixth cranial nerve palsy; dizziness; change in hearing (muffled or distant hearing, distorted hearing, or echoes); visual blurring; photophobia; interscapular pain; facial numbness or weakness; radicular upper-limb symptoms: ${ }^{32}$ visual field cut (superior binasal); ${ }^{20}$ or galactorrhea. ${ }^{59}$ Single cases of the following have been reported: stupor $;^{38}$ parkinsonism, ataxia, and bulbar symptoms; ${ }^{35}$ and encephalopathy. ${ }^{4}$ When cervical, thoracic, or lumbar spine pain is present, the CSF level of the leak may not necessarily correspond with the level of the pain (indeed it often does not). Therefore this often, although not always, proves to be a false localizing sign.

\section{DIAGNOSTIC MODALITIES}

\section{Cerebrospinal Fluid Examination}

Cerebrospinal fluid pressure is typically found to be very low, sometimes atmospheric, and occasionally even negative. In some patients, however, pressures may be "low normal," and yet in others with persistent symptomatic CSF leaks the CSF opening pressures may be consistently within normal limits. ${ }^{29}$ In patients with intermittent or variable CSF leaks, variable pressures may be recorded at different times in the same patient ranging from very low, to low normal to entirely normal. Analysis of CSF samples also shows considerable variability. The fluid is typically clear and colorless but sometimes may be xanthochromic. Levels of protein may be normal or high; protein concentrations up to $100 \mathrm{mg} / \mathrm{dl}$ are not uncommon but sometimes much higher concentrations can be seen, rarely even up to $1000 \mathrm{mg} / \mathrm{dl} .{ }^{32}$ Cerebrospinal fluid cell count is also subject to considerable variability. The erythrocyte count may be normal or elevated (as high as a few to several hundreds). Leukocyte count may be normal but a primarily lymphocytic pleocytosis of up to 50 cells $/ \mathrm{mm}^{3}$ is common. Higher values are not rare and pleocytosis as high as 220 cells $/ \mathrm{mm}^{3}$ been noted in documented CSF leaks in which there is no evidence of infection or inflammation. ${ }^{31,32}$ Cytological and microbiological features in the CSF are always negative, and CSF glucose is never low in proportion to plasma glucose concentration.

\section{Head CT Scanning}

In CSF leaks, head CT scanning is of limited value and typically demonstrates negative results. Only occasionally does it demonstrate subdural fluid collections or increased tentorial enhancement. ${ }^{37,51}$

\section{Indium $^{I 11}$ Radioisotope Cisternography}

In CSF leaks, typically the radioactivity produced by the radioisotope produced intrathecally at the lumbar level does not extend much beyond the basal cisterns and cannot be visualized over the cerebral convexities even at 24 or 48 hours postinjection. Less commonly it may demonstrate the level of the leak (Fig. 1) or the larger diverticulum. ${ }^{13}$ A common observation is early appearance of radioactivity in the kidneys and urinary bladder. This should not be misinterpreted as a manifestation of increased CSF reabsorption, ${ }^{33,57}$ as the radioisotope hardly reaches the brain convexities to be reabsorbed.

Early clearance of radioactivity is an indication of a CSF leak, which has allowed extravasation of radioiso- 


\section{Volume depletion in CSF}


Fig. 1. Various neuroimaging studies in cases of CSF volume depletion. A: Gadolinium-enhanced coronal MR image demonstrating diffuse pachymeningeal gadolinium enhancement. B: Nonenhanced coronal MR image, obtained in the same patient as in Fig. 1A, demonstrating bilateral subdural fluid collections (arrows). C: Axial gadolinium-enhanced MR image revealing diffuse nonnodular, uninterrupted pachymeningeal gadolinium enhancement. Note that leptomeninges around the brainstem show no evidence of gadolinium enhancement. $\quad \mathrm{D}$ and E: Gadolinium-enhanced $\mathrm{T}_{1}$ weighted coronal MR images obtained in a patient with communicating hydrocephalus before (D) and after (E) placement of a shunt. Postshunting, the ventricles are smaller. The shunt was overdraining and had caused orthostatic headaches. Note the diffuse pachymeningeal enhancement involving both supra- and infratentorial pachymeninges. Also note the enlargement of superior sagittal sinus in postshunting (E) compared with preshunting (D) (arrows). Sagittal MR image $(\mathrm{F})$ demonstrating decent of the cerebellar tonsils and a coronal image $(\mathrm{G})$ obtained in the same patient demonstrating enlargement of the pituitary gland (asterisks), flattening and tenting of the optic chiasm (arrow), and partial obliteration of perichiasmatic cistern in a patient with CSF leak. $\mathrm{H}$ and $\mathrm{I}$ : After cessation of the leak and resolution of clinical manifestations, the MR imaging abnormalities have also reversed. Note that the pituitary is now smaller (asterisk in $\mathrm{H}$ ) and the optic chiasm is free (arrow in $\mathrm{H}$ ) and the perichiasmatic cisterns are not compromised. The decent of the cerebellar tonsils also has been reversed (I compared with F). J: Myelography revealing multiple meningeal diverticula (arrows). K: Computerized tomography myelography revealing extradural leakage of contrast medium (arrows). L: Computerized tomography myelography demonstrating bilateral "dog ear"-shaped collections of extraarachnoid or extradural contrast medium (arrows). M: Indium ${ }^{111}$ cisternography demonstrating activity in the basal cisterns (arrowhead) and detection of extraarachnoid/extradural activity in the thoracic region bilaterally (arrows). 


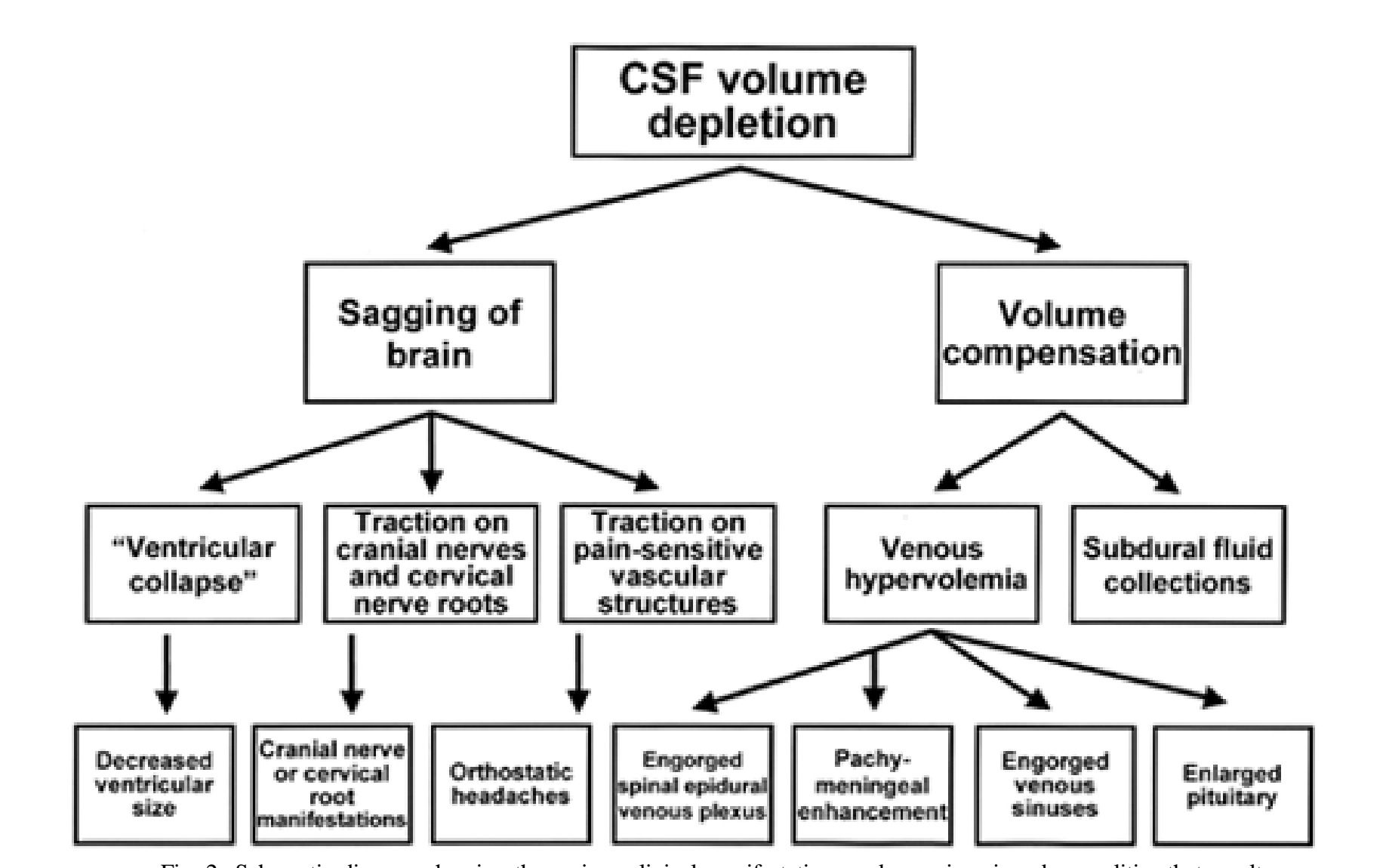

Fig. 2. Schematic diagram showing the various clinical manifestations and neuroimaging abnormalities that result from depletion of CSF volume.

tope in the paraspinal tissues, its early entrance into the venous system, and, therefore, its early clearance by the kidney and its early appearance in the urinary bladder.

\section{Magnetic Resonance Imaging}

Abnormalities demonstrated on head MR imaging studies in patients with CSF volume depletion include: diffuse pachymeningeal enhancement (both supra- and infratentorial, bilateral, linear and nonnodular, typically uninterrupted, often thick and obvious, sometimes very thin, but always without leptomeningeal involvement, ${ }^{31,36} \mathrm{Fig}$. 1A, C, and $\mathrm{E}$ ); sinking or sagging of the brain (descent of the cerebellar tonsils sometimes mimicking Chiari I malformation, ${ }^{1}$ (Fig. 1F); decrease in the size of prepontine and perichiasmatic cisterns (Fig 1G); inferior displacement of the optic chiasm, (Fig. 1G); crowding of posterior fossa; subdural fluid collections (uni- or bilateral and typically over the convexities of the brain, typically 2 to $7 \mathrm{~mm}$ in maximum thickness without compression or effacement of the underlying sulci, and with variable MR signal intensity depending on fluid protein concentration or presence of blood, Fig. 1B); decrease in size of the ventricles (sometimes obvious, sometimes quite subtle and only noted when pre- and postrecovery MR images are compared); pituitary enlargement (sometimes mimicking pituitary adenoma or hyperplasia, ${ }^{27}$ Fig. $1 \mathrm{G}$ ); and enlarged/ engorged venous sinuses (Fig. 1E). ${ }^{3}$

Abnormalities demonstrated on spine MR imaging studies include: the presence of extraarachnoid/extradural fluid, ${ }^{32,39}$ meningeal diverticula (of various size, single or multiple, and may or may not be the actual site of the leak), spinal pachymeningeal enhancement, ${ }^{25}$ and enlargement and prominence of epidural venous plexus. Sometimes the actual site of the CSF leak can be detected using spine MR imaging, but so far CT myelography with water-soluble contrast is the study of choice for demonstrating the site of the CSF leaks.

\section{Myelography and CT Myelography}

Myelography and CT myelography can demonstrate meningeal diverticula and extraarachnoid-dural leakage of contrast. Computerized tomography myelography is the best test for demonstrating site of CSF leak (Fig. 1J-L). Considering that the leaks may be rapid or slow, early and delayed CT cuts may be necessary and should be obtained at each spinal level; however, if cisternography or spine MR imaging has demonstrated the approximate level of the leak, then CT cuts may be concentrated in this zone.

\section{MECHANISM OF MR ABNORMALITIES AND CLINICAL MANIFESTATIONS}

The various clinical manifestations and neuroimagingdocumented abnormalities resulting from depletion of CSF volume are shown in Fig. 2. Loss of CSF volume in the presence of an intact skull, according to the Monro- 
Volume depletion in CSF

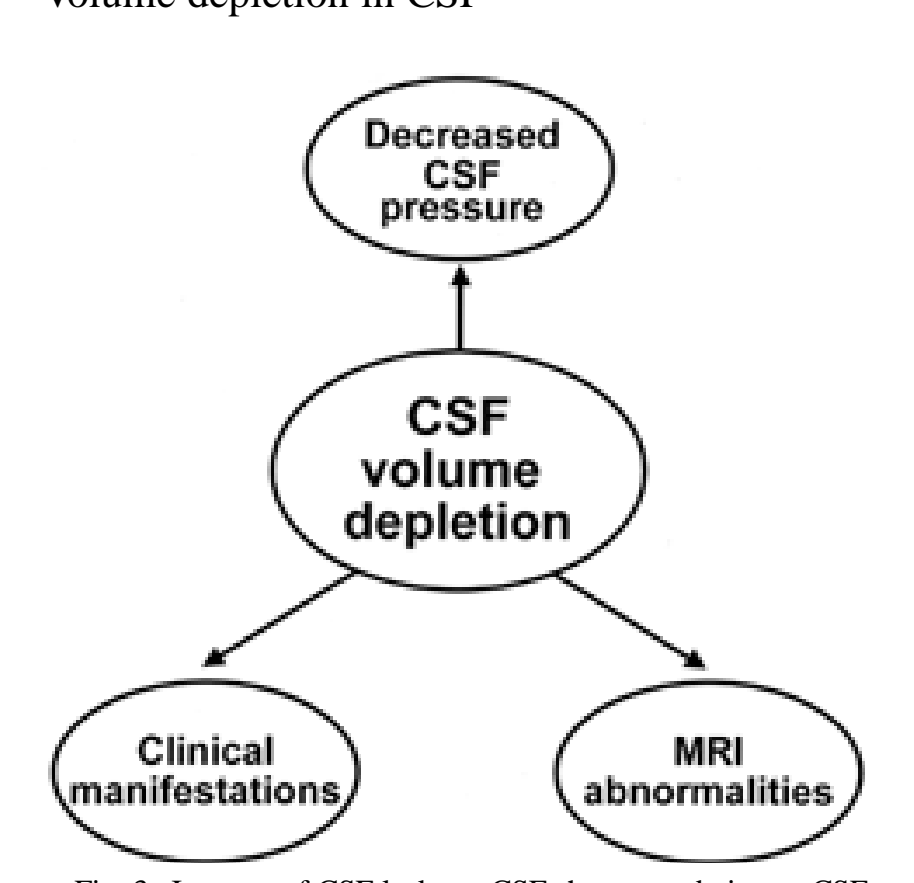

Fig. 3. In cases of CSF leaks or CSF shunt overdrainage, CSF volume depletion is the core of the problem as the independent variable. Cerebrospinal fluid pressure, MR imaging-documented abnormalities, and clinical manifestations show considerable variability as dependent variables.

Kellie doctrine, ${ }^{46}$ requires volume compensation by an increase in intracranial blood volume. This is primarily reflected in the venous system, leading to meningeal venous hyperemia (manifested by gadolinium enhancement because the leptomeninges have blood-brain barriers and pachymeninges do not), enlargement of venous sinuses and pituitary gland, and prominence and engorgement of the spinal epidural venous plexus. Analysis of biopsy samples supports the notion that the dural meningeal abnormalities represent only secondary phenomena in reaction to CSF volume or pressure changes. ${ }^{31}$

Another consequence of CSF volume depletion is sinking of the brain and ventricular collapse that lead to a decrease in size of the ventricles, descent of the cerebellar tonsils, crowding of posterior fossa, and obliteration of some of the subarachnoid cisterns.

The major clinical consequence of sagging of the brain is traction and distortion of pain-sensitive suspending structures of the brain as well as development of orthostatic headaches. Similarly, compression of the cranial nerves (fifth, sixth, and seventh) is likely responsible for palsy that is sometimes noted to afflict these nerves. Visual blurring and visual field cuts likely result from compression or vascular congestion of intracranial portions of optic nerves. ${ }^{20}$ Galactorrhea and increased prolactin are likely caused by distortion of pituitary stalk. Dizziness and changes in hearing may be related to stretching of the eighth cranial nerve or, alternatively, to pressure change in the perilymphatic fluid of the inner ear. Radicular upperlimb symptoms may be a consequence of stretching of cervical nerve roots or the presence of structural abnormalities at the nerve root sleeve level. Stupor has been related to diencephalic compression and ataxia to compression of posterior fossa elements.

\section{TREATMENT OPTIONS}

No definite standard approaches have been established. Bed rest, hydration, caffeine or theophylline, steroid medications, abdominal binders, epidural blood patch, continuous epidural saline infusion, epidural infusion of dextran, placement of a CSF shunt, and surgical repair of the leaks are some of the modalities that have been implemented. Many patients fortunately improve spontaneously. The beneficial effect of recumbency in sealing the leak has not been proven. However, because of the often orthostatic nature of the headache, many of the patients choose to remain recumbent as much as possible. Similarly, the effectiveness of hydration or overhydration has not been definitely established. ${ }^{53}$ The effectiveness of caffeine and theophylline therapy demonstrated in some studies, ${ }^{17}$ by and large is often unimpressive and not durable. Evidence for the efficacy of steroid therapy is at best sporadic, and a substantial lasting effect is doubtful.

When the initial conservative management fails, an epidural blood patch procedure is the treatment of choice. ${ }^{6,8,17}$. 43,49,55 Its effect is essentially twofold: 1) an immediate effect related simply to volume replacement by compressing the dura; and 2) a more latent effect related to sealing of the dural defect. ${ }^{52}$ Approximately half of the patients require more than one application of a blood patch. In our experience some patients have required as many as four to six epidural blood patches.

Epidural saline infusion has produced varying results. ${ }^{15,42,54}$ Such therapy can be considered (with limited expectations) in some of the patients in whom repeated blood patch procedures have failed, especially if the site of the leak has not been found, which excludes a surgical approach.

Surgery in well-selected cases should be considered when conservative measures and epidural blood patches have failed to resolve the CSF leakage. ${ }^{32,47}$ The technical aspects will not be discussed here; however, we will stress that ideally the site of the leak should be demonstrated preoperatively. Although dural tears, holes, and leaking diverticula can be usually repaired without significant difficulty, some cases are not entirely straightforward. The surgeon may encounter the leaking CSF but may not be able to find the exact site of the leak; a patchlike dural defect with attenuated margins may be detected that may not yield to suturing; or a leak may be present at more than one site. The presence of a meningeal diverticulum, even when large, may not necessarily indicate the site of the leak unless neuroimaging studies have demonstrated extravasation of contrast or fluid in that area.

\section{BROADENING CLINICONEUROIMAGING SPECTRUM}

Due to advances in neurodiagnostic techniques, particularly MR imaging, increasing numbers of cases of CSF volume depletion due to CSF shunt overdrainage and particularly due to spontaneous CSF leaks have been diagnosed. Several attendant points have come to light: 1) In contrast to what was thought for years, the clinical picture of CSF leakage or volume depletion is not necessarily identical to that in post-spinal tap headaches. Headache in some patients lacks orthostatic features and manifests as a 
TABLE 1

Clinical neuroimaging syndromes in CSF volume depletion*

\begin{tabular}{ll}
\hline \hline \multicolumn{1}{c}{ Type } & \multicolumn{1}{c}{ Description } \\
\hline I $\quad$ (classic) & $\begin{array}{c}\text { headache present; head MR findings abnormal; } \\
\text { low CSF pressure } \\
\text { headache present; head MR findings abnormal; } \\
\text { normal CSF pressure } \\
\text { II (normal pressure) } \\
\text { III (normal meninges) present; normal meninges on head } \\
\text { MR; low CSF pressure } \\
\text { IV (acephalgic) }\end{array}$ \\
$\begin{array}{l}\text { headache absent; head MR findings abnormal; } \\
\text { low CSF pressure }\end{array}$ \\
\hline
\end{tabular}

* The headache is typically orthostatic, sometimes a lingering chronic daily headache, and it may be worse when the patient stands upright.

lingering, chronic, daily headache, particularly in longstanding cases, although sometimes these headaches may be more prominent when the patient is up and about, and their improvement with recumbency is not quick or complete. 2) In some patients with typical clinical and neuroimaging features of the disease and documented CSF leaks, opening pressures that are consistently within limits of normal may be observed. ${ }^{29} 3$ ) In some patients with typical clinical features of the disease, documented CSF leakage and low CSF pressures, evidence of abnormal pachymeningeal enhancement may not be demonstrated on MR imaging. ${ }^{28}$ 4) Some patients in whom there is evidence of diffuse pachymeningeal enhancement, low CSF pressures, and CSF leakage or shunt overdrainage may experience no headaches. ${ }^{18}$

Clinical and neuroimaging findings indicate that CSF volume depletion is the independent variable, whereas clinical manifestations, CSF pressures, and neuroimaging findings are the three main variables dependent on the loss of CSF volume (Fig. 3). The term "CSF volume depletion" identifies best the core of the problem in this disorder (that is, the loss of CSF volume). Terms such as "intracranial hypotension" or "low CSF pressure headache" no longer appear broad enough to embrace all of the clinical and neuroimaging variations observed in this entity.

Although single case reports of unusual clinical presentations of CSF leaks have appeared in the literature $4,35,38,59$ and more single cases of unusual presentations will likely be reported, CSF volume depletion essentially presents with four different clinical/neuroimaging syndromes (Table 1). The CSF volume depletion as the independent variable is always present. The three major dependent variables (headaches, pachymeningeal enhancement, and low CSF pressure) show significant variation and may or may not be present. In Type I CSF volume depletion or the classic form, all three components are demonstrated. In Type II (normal pressure) CSF pressure is not low. In Type III (normal meninges) there is no abnormal pachymeningeal enhancement, and in Type IV (acephalgic) headache is absent.

\section{References}

1. Atkinson LD, Weinshenker BG, Miller GM, et al: Acquired Chiari I malformation secondary to spontaneous spinal cerebrospinal fluid leakage and chronic intracranial hypotension syndrome in seven cases. J Neurosurg 88:237-242, 1998
2. Baker CC: Headache due to spontaneous low spinal fluid pressure. Minn Med 66:325-328, 1983

3. Bakshi R, Mechtler LL, Kamran S, et al: MRI findings in lumbar puncture headache syndrome: abnormal dural-meningeal and dural venous sinus enhancement. Clin Imaging 23:73-76, 1999

4. Beck CE, Rizk NW, Kiger LT, Spencer D, et al: Intracranial hypotension presenting with severe encephalopathy. Case report. J Neurosurg 89:470-473, 1998

5. Bell WE, Joynt RJ, Sahs AL: Low spinal fluid pressure syndromes. Neurology 10:512-521, 1960

6. Crawford JS: Epidural blood patch. Anaesthesia 40:381, 1985

7. Davenport RJ, Chataway SJ, Warlow CP: Spontaneous intracranial hypotension from a CSF leak in a patient with Marfan's syndrome. J Neurol Neurosurg Psychiatry 59:516-519, 1995

8. DiGiovanni AJ, Galbert MW, Wahle WM: Epidural injection of autologous blood for postlumbar-puncture headache. II. Additional clinical experiences and laboratory investigation. Anesth Analg 51:226-232, 1972

9. Dillon WP, Fishman RA: Some lessons learned about the diagnosis and treatment of spontaneous intracranial hypotension. AJNR 19:1001-1002, 1998 (Editorial)

10. Fattori R, Nienaber CA, Descovich B, et al: Importance of dural ectasia in phenotypic assessment of Marfan's syndrome. Lancet 354:910-913, 1999

11. Fishman RA: Cerebrospinal Fluid in Diseases of the Nervous System, ed 2. Philadelphia: WB Saunders, 1992

12. Fishman RA, Dillon WP: Dural enhancement and cerebral displacement secondary to intracranial hypotension. Neurology 43:609-611, 1993

13. Front D, Penning L: Subcutaneous extravasation of CSF demonstration by scinticisternography. J Nucl Med 15:200-201, 1974

14. Fukutake T, Sakakibara R, Mori M, et al: Chronic intractable headache in a patient with Marfan's syndrome. Headache 37: 291-295, 1997

15. Gibson BE, Wedel DJ, Faust RJ, et al: Continuous epidural saline infusion for the treatment of low CSF pressure headache. Anesthesiology 68:789-791, 1988

16. Gormley JB: Treatment of postspinal headache. Anesthesiology 21:565-566, 1960

17. Grant R, Condon B, Patterson J, et al: Changes in cranial CSF volume during hypercapnia and hypocapnia. J Neurol Neurosurg Psychiatry 52:218-222, 1989

18. Hochman MS, Naidich TP: Diffuse meningeal enhancement in patients with overdraining, long-standing ventricular shunts. Neurology 52:406-409, 1999

19. Hochman MS, Naidich TP, Kobetz SA, et al: Spontaneous intracranial hypotension with pachymeningeal enhancement on MRI. Neurology 42:1628-1630, 1992

20. Horton JC, Fishman RA: Neurovisual findings in the syndrome of spontaneous intracranial hypotension from dural cerebrospinal fluid leak. Ophthalmology 101:244-251, 1994

21. Huber M: [Spontaneous hypoliquorrhea. Report on 7 personal observations.] Schweiz Arch Neurol Neurochir Psychiatr 106:9-23, 1970 (Ger)

22. Labadie EL, van Antwerp J, Bamford CR: Abnormal lumbar isotope cisternography in an unusual case of spontaneous hypoliquorrheic headache. Neurology 26:135-139, 1976

23. Lasater, GM: Primary intracranial hypotension. The low spinal fluid pressure syndrome. Headache 10:63-66, 1970

24. Marcelis J, Silberstein SD: Spontaneous low cerebrospinal fluid pressure headache. Headache 30:192-196, 1990

25. Moayeri NN, Henson JW, Schaefer PW, et al: Spinal dural enhancement on magnetic resonance imaging associated with spontaneous intracranial hypotension. Report of three cases and review of the literature. J Neurosurg 88:912-918, 1998

26. Mokri B: Spontaneous cerebrospinal fluid leaks: from intracranial hypotension to cerebrospinal fluid hypovolemia- evolution of a concept. Mayo Clin Proc 74:1113-1123, 1999 


\section{Volume depletion in CSF}

27. Mokri B, Atkinson JLD: False pituitary tumor in spontaneous cerebrospinal fluid leak. Ann Neurol 46:475, 1999 (Abstract)

28. Mokri B, Atkinson JLD, Dodick DW, et al: Absent pachymeningeal gadolinium enhancement on cranial MRI despite symptomatic CSF leak. Neurology 53:402-404, 1999

29. Mokri B, Hunter SF, Atkinson JLD, et al: Orthostatic headaches caused by CSF leak but with normal CSF pressures. Neurology 51:786-790, 1998

30. Mokri B, Krueger BR, Miller GM, et al: Meningeal gadolinium enhancement in low-pressure headaches. Ann Neurol 30: 294-295, 1991 (Abstract)

31. Mokri B, Parisi JE, Scheithauer BW, et al: Meningeal biopsy in intracranial hypotension: meningeal enhancement on MRI. Neurology 45:1801-1807, 1995

32. Mokri B, Piepgras DG, Miller GM: Syndrome of orthostatic headaches and diffuse pachymeningeal gadolinium enhancement. Mayo Clin Proc 72:400-413, 1997

33. Molins A, Alvarez J, Sumalla J, et al: Cisternographic pattern of spontaneous liquoral hypotension. Cephalalgia 10:59-65, 1990

34. Murros K, Fogelholm R: Spontaneous intracranial hypotension with slit ventricles. J Neurol Neurogurg Psychiatry 46: 1149-1151, 1983

35. Pakiam AS, Lee C, Lang AE: Intracranial hypotension with parkinsonism, ataxia, and bulbar weakness. Arch Neurol 56: 869-872, 1999

36. Pannullo SC, Reich JB, Krol G, et al: MRI changes in intracranial hypotension. Neruology 43:919-926, 1993

37. Pavlin DJ, McDonald JS, Child B, et al: Acute subdural hematoma-an unusual sequela to lumbar puncture. Anesthesiology 51:338-340, 1979

38. Pleasure SJ, Abosch A, Friedman, et al: Spontaneous intracranial hypotension resulting in stupor caused by diencephalic compression. Neurology 50:1854-1857, 1998

39. Rabin BM, Roychowdhury S, Meyer JR, et al: Spontaneous intracranial hypotension: spinal MRI findings. AJNR 19: 1034-1039, 1998

40. Rando TA, Fishman RA: Spontaneous intracranial hypotension: report of two cases and review of the literature. Neurology 42: 481-487, 1992

41. Raskin NH: Lumbar puncture headache: a review. Headache 30:197-200, 1990

42. Rice GG, Dabbs CH: The use of peridural and subarachnoid injections of saline solution in the treatment of severe postspinal headaches. Anesthesoiology 11:17-23, 1950

43. Rosenberg PH, Heavner JE: In vitro study of the effect of epidural blood patch on leakage through a dural puncture. Anesth Analg 64:501-504, 1985

44. Sable SG, Ramadan NM: Meningeal enhancement and low CSF pressure headache: an MRI study. Cephalalgia 11: 275-276, 1991
45. Schaltenbrand G: Neure Anschauungen zur Pathophyiologie der Liquorzirkulation. Zentrablbl Neurochir 3:290-300, 1938

46. Schaltenbrand G: Normal and pathological physiology of the cerebrospinal fluid circulation. Lancet 1:805-808, 1953

47. Schievink WI, Morreale VM, Atkinson JLD, et al: Surgical treatment of spontaneous spinal cerebrospinal fluid leaks. J Neurosurg 88:243-246, 1998

48. Schievink WI, Torres VE: Spinal meningeal diverticula in autosomal dominant polycystic kidney disease. Lancet 349: 1223-1224, 1997

49. Seebacher J, Ribeiro V, LeGuillou JL, et al: Epidural blood patch in the treatment of post dural puncture headache: a double blind study. Headache 29:630-632, 1989

50. Silberstein SD, Marcelis J: Headache associated with changes in intracranial pressure. Headache 32:84, 1992

51. Sipe JC, Zyroff J, Waltz TA: Primary intracranial hypotension and bilateral isodense subdural hematomas. Neurology 31: 334-337, 1981

52. Szeinfeld M, Ihmeidan IH, Moser MML, et al: Epidural blood patch: evaluation of the volume and spread of blood injected into the epidural space. Anesthesiology 64:820-822, 1986

53. Tourtellotte WW, Haerer AF, Heller GL, et al: Post-Lumbar Puncture Headaches. Springfield, IL: Charles C Thomas, 1964

54. Usubiaga JE, Usubiaga LE, Brea LM, et al: Effect of saline injections on epidural and subarachnoid space pressures and relation to postspinal anesthesia headache. Anesth Analg 46: 293-296, 1967

55. Vakharia SB, Thomas PS, Rosenbaum AE, et al: Magnetic resonance imaging of cerebrospinal fluid leak and tamponade effect of blood patch in post-dural puncture headache. Anesth Analg 84:585-590, 1997

56. Vishteh AG, Schievink, Baskin JJ, et al: Cervical bone spur presenting with spontaneous intracranial hypotension. Case report. J Neurosurg 89:483-484, 1998

57. Weber WE, Heidendahl GA, de Krom MC: Primary intracranial hypotension and abnormal radionuclide cisternography: report of a case and review of the literature. Clin Neurol Neurosurg 93:55-60, 1991

58. Woltman HW: Headache: a consideration of some of the more common types. Med Clin North Am 24:1159-1170, 1940

59. Yamamoto M, Suehiro T, Nakata H, et al: Primary low cerebrospinal fluid pressure syndrome associated with galactorrhea Intern Med 32:228-231, 1993

Manuscript received May 15, 2000.

Accepted in final form June 8, 2000.

Address reprint requests to: Bahram Mokri, M.D., Department of Neurology, Mayo Clinic, 200 First Street, S.W., Rochester, Minnesota 55905. 